\title{
Hepatitis B Virus (HBV) Infection in Pregnancy: Knowledge and Practice of Care Providers in Nigeria
}

\author{
Adewale S. Adeyemi ${ }^{1}$, Adeola F. Afolabi ${ }^{1}$, Adeleye A. Adeomi ${ }^{2}$ \\ ${ }^{1}$ Department of Obstetrics and Gynaecology, College of Health Sciences, Ladoke Akintola University of \\ Technology, Ogbomoso, Nigeria \\ ${ }^{2}$ Department of Community Medicine, Ladoke Akintola University of Technology Teaching Hospital, Ogbomoso, \\ Nigeria \\ Email: drafolabiaf@gmail.com
}

Received 8 May 2014; revised 5 June 2014; accepted 1 July 2014

Copyright (C) 2014 by authors and Scientific Research Publishing Inc.

This work is licensed under the Creative Commons Attribution International License (CC BY). http://creativecommons.org/licenses/by/4.0/

(c) (i) Open Access

\begin{abstract}
Purpose: To determine the practice of obstetric care providers regarding routine screening for hepatitis $B$ virus infection, and to assess their knowledge of the management of the positive pregnant women. Methods: A cross sectional descriptive study of obstetric care providers in southwestern Nigeria. Mean and standard deviation was used to summarize continuous variables while frequency and percentage was used for categorical variables. Categorical variables were compared with chi-square test and Fisher's exact tests as appropriate; while continuous variables were compared using the t-test. The level of statistical significance was set at $P \leq 0.05$. Scoring of the outcome variables for knowledge was done, and the score categorized into good and poor knowledge, depending on if the respondent scored above or below the mean score. Results: Three hundred and eighty-one (67.4\%) of the care givers routinely screen pregnant women for the serum marker (HBSAg) of HBV infection. Two hundred and seventy-four (48.5\%) of the respondents had good knowledge score of the management of HBV infection in pregnancy. Routine screening for HBV infection was significantly associated with age $(p=0.002)$, years of practice $(p<0.001)$, specialty $(p=0.001)$ and professional cadre $(p<0.001)$, while knowledge was significantly associated with age $(p=0.012)$, years of practice $(p=0.003)$, specialty $(p=0.047)$ and types of practice $(p=0.014)$. Conclusion: Screening for HBV infection in pregnant women is not universal in southwestern Nigeria, and the care providers have poor knowledge of the management of the positive mothers.
\end{abstract}

\section{Keywords}

HBV Infection, Obstetric Care Providers, Routine Screening, Management, Nigeria 


\section{Introduction}

Hepatitis B Virus is the most virulent and most versatile of all hepatotropic viruses and probably the most prevalent of all viruses that infect humans [1]. It is a major public health problem, and it is estimated that over 300 million people are chronic HBV carriers worldwide [2]. HBV infection is relatively uncommon in some areas like Western Europe; however, the infection is endemic in African and Asian countries [3] [4]. Nigeria is being classified as a hyper endemic area for HBV infection, with an estimated $12 \%$ of the total population being chronic carriers [5].

HBV infection causes an array of clinical syndromes such as acute hepatitis, chronic non-progressive hepatitis, and progressive disease ending in cirrhosis, fulminant hepatitis with massive liver necrosis, asymptomatic carrier, and hepatocellular carcinoma [1]. The mode of transmission of HBV differs depending on the state of endemicity. In a low endemic area (e.g. Europe, America and Canada), transfusion of blood and its products, dialysis, intravenous drug abuse and homosexual activity constitute the primary source of infection, and as such neonatal infection is uncommon [6]; whereas most adult carriers are said to have acquired the infection perinatally in endemic regions like Africa south of Sahara, southeast Asia, and south America [7].

The probability of developing the carrier state following HBV infection is the greatest in early life and decreases with increasing age. Up to $90 \%$ of babies born to carrier mothers may become carriers and they are at a very high risk of developing chronic liver disease at a younger age [8]. In the light of the foregoing, the Centre for Disease Control and prevention (CDC) more than two decades ago recommended that all pregnant women be screened for the marker of active HBV infection, hepatitis B surface antigen (HBSAg) [9]. Worldwide hepatitis $B$ vaccination has been integrated into the routine vaccination schedule for infants as part of the World Health Organization's Expanded Program on Immunization [10]. The present study therefore, is to assess the practice of pregnant women care givers as regard routine screening for HBV infection in the antenatal period, and also to assess their knowledge of the management of HBV infection in pregnancy and in the perinatal period.

\section{Materials and Methods}

A cross sectional descriptive study of medical doctors provides obstetric care for pregnant women in Nigeria. Three states were randomly selected out of the six states in southwestern Nigeria; the states selected were: Oyo, Osun and Ondo. Data was collected using a self-administered structured questionnaire which was pretested among community medicine resident doctors of Ladoke Akintola University of Technology Teaching Hospital, Ogbomoso, Oyo state, and necessary adjustments made to the questionnaire accordingly. A total of 605 questionnaires were administered using multi-stage sampling technique, but 565 were properly filled and returned giving a response rate of $93.4 \%$.

Research assistants were trained to help in data collection. Ethical approval was obtained from ethics committee of Ladoke Akintola University of Technology Teaching Hospital, Ogbomoso, and written consent was obtained from the respondents. The study covered a period of three months, $1^{\text {st }}$ March to $30^{\text {th }}$ June, 2013.

Data management was done using SPSS version 17. Mean and standard deviation was used to summarize continuous variables while frequency and percentage was used for categorical variables. Categorical variables were compared with chi-square test and Fisher's exact tests as appropriate; while continuous variables were compared using the t-test. The level of statistical significance was set at $\mathrm{p} \leq 0.05$. The outcome variables for knowledge was scored; a correct answer scored two, while a wrong answer scored zero, and a not sure answer scored one; average score was calculated, and the score categorized into good and poor knowledge, depending on if the respondent scored above or below the mean score.

\section{Results}

The socio-demographic details of the respondents are as shown in Table 1 . Three hundred and eighty-one (67.4\%) of the care givers routinely screen pregnant women for the serum marker (HBSAg) of HBV infection, while 184 (32.6\%) do not. Most of the respondents (473, 83.7\%) said that HBV antibodies presence should be determined in the serum of women who tested positive for the marker (HBSAg), while 55 (9.7\%) said women should not be tested, and 37 (6.5\%) were not sure if the women should be tested for the antibodies. Many of the doctors (319, 56.5\%) answered in the affirmative that pregnant women who test positive for HBSAg could commence drug treatment, while 187 (33.1\%) responded that drug treatment should not commence, and 59 
Table 1. Socio-demographic characteristics of respondents.

\begin{tabular}{|c|c|c|}
\hline Variables & Frequency & Percentage \\
\hline \multicolumn{3}{|l|}{ Age groups (in years) } \\
\hline $20-29$ & 117 & 20.7 \\
\hline $30-39$ & 328 & 58.1 \\
\hline $40-49$ & 73 & 12.9 \\
\hline $50-59$ & 32 & 5.7 \\
\hline $60-69$ & 15 & 2.7 \\
\hline Mean Age & $35.5 \pm 8.3$ & \\
\hline \multicolumn{3}{|l|}{ Professional cadre } \\
\hline Medical officer & 445 & 78.8 \\
\hline Specialist (resident doctors and consultants) & 120 & 21.2 \\
\hline \multicolumn{3}{|l|}{ Type of practice } \\
\hline Public & 348 & 61.6 \\
\hline Private & 217 & 38.4 \\
\hline \multicolumn{3}{|l|}{ Years of practice } \\
\hline$<10$ & 425 & 75.2 \\
\hline $10-19$ & 83 & 14.7 \\
\hline $20-29$ & 34 & 6.0 \\
\hline $30-39$ & 21 & 3.7 \\
\hline$\geq 40$ & 2 & 0.4 \\
\hline Mean & $7.8 \pm 7.8$ & \\
\hline \multicolumn{3}{|l|}{ Number of pregnant women per week } \\
\hline$<10$ & 103 & 18.2 \\
\hline $10-49$ & 260 & 46.0 \\
\hline $50-99$ & 117 & 20.7 \\
\hline$\geq 100$ & 85 & 15.0 \\
\hline \multicolumn{3}{|l|}{ State of Practice } \\
\hline Оуо & 190 & 33.6 \\
\hline Osun & 263 & 46.5 \\
\hline Ondo & 112 & 19.8 \\
\hline
\end{tabular}

(10.4\%) were not sure if drug treatment can be commenced. HBV vaccination for pregnant women who test negative for HBSAg was met with a "NO" answer from 345 (61.1\%) of the doctors, while 171(30.3\%) answered "YES", and 49 (8.7\%) were not sure if pregnant women should be vaccinated. Almost all the respondents (529, 93.6\%) knew there can be mother to child transmission (MTCT) of HBV, while 21 (3.7\%) did not know there can be MTCT of HBV, and 15 (2.7\%) were not sure if HBV can be transmitted from mother to child.

Four hundred and thirty-three (76.6\%) of the respondents agreed that HBV immunoglobulin (HBIG) should be given at birth to the babies of HBSAg positive mothers, while 83 (14.7\%) said the HBIG should not be given to the babies, and 49 (8.7\%) were not sure if the HBIG should be given. Only 178 (31.5\%) of the respondents knew that babies born by HBSAg mothers should be given HBV vaccination within 12 hours of birth, while 387 (68.5\%) were not aware of the timing of vaccination of the babies. Three hundred and fifty-six $(63.0 \%)$ responded in the affirmative that some drugs being used for the treatment of Human Immunodeficiency virus (HIV) could be used for the treatment of HBSAg positive pregnant women, while 34 (6.0\%) responded "NO", and 175 (31.0\%) were not sure if the drug could be used for HBSAg positive women. The knowledge score of the respondents about the management of HBV infection in pregnancy ranged between 5 and 24, with a mean of $13.3 \pm 2.7$. Two hundred and seventy-four (48.5\%) of the respondents had good knowledge score, and the rest 
(51.5\%) had poor knowledge score about the management of HBV infection in pregnancy.

Bivariate analysis showed that the practice of routine screening for HBV infection by care givers was significantly associated with their age $(p=0.002)$, years of practice $(p<0.001)$, specialty $(p=0.001)$ and professional cadre $(\mathrm{p}<0.001)$ as shown in Table 2. The significant relationships between age, years of practice and routine screening for HBV were further corroborated by the t-test for two independent samples as shown in Table 2.

Table 3 shows the relationship between the categorized knowledge of respondents and socio-demographic characteristics. The respondents' knowledge was significantly associated with their age $(p=0.012)$, years of practice $(p=0.003)$, specialty $(p=0.047)$ and types of practice $(p=0.014)$. The arithmetic means of the ages and years of practice of those with poor and good knowledge were also compared using the t-test, and there were significant differences between them (Table 3).

Table 2. Relationship between respondents' practice of routine screening for HBV and their socio-demographic characteristics.

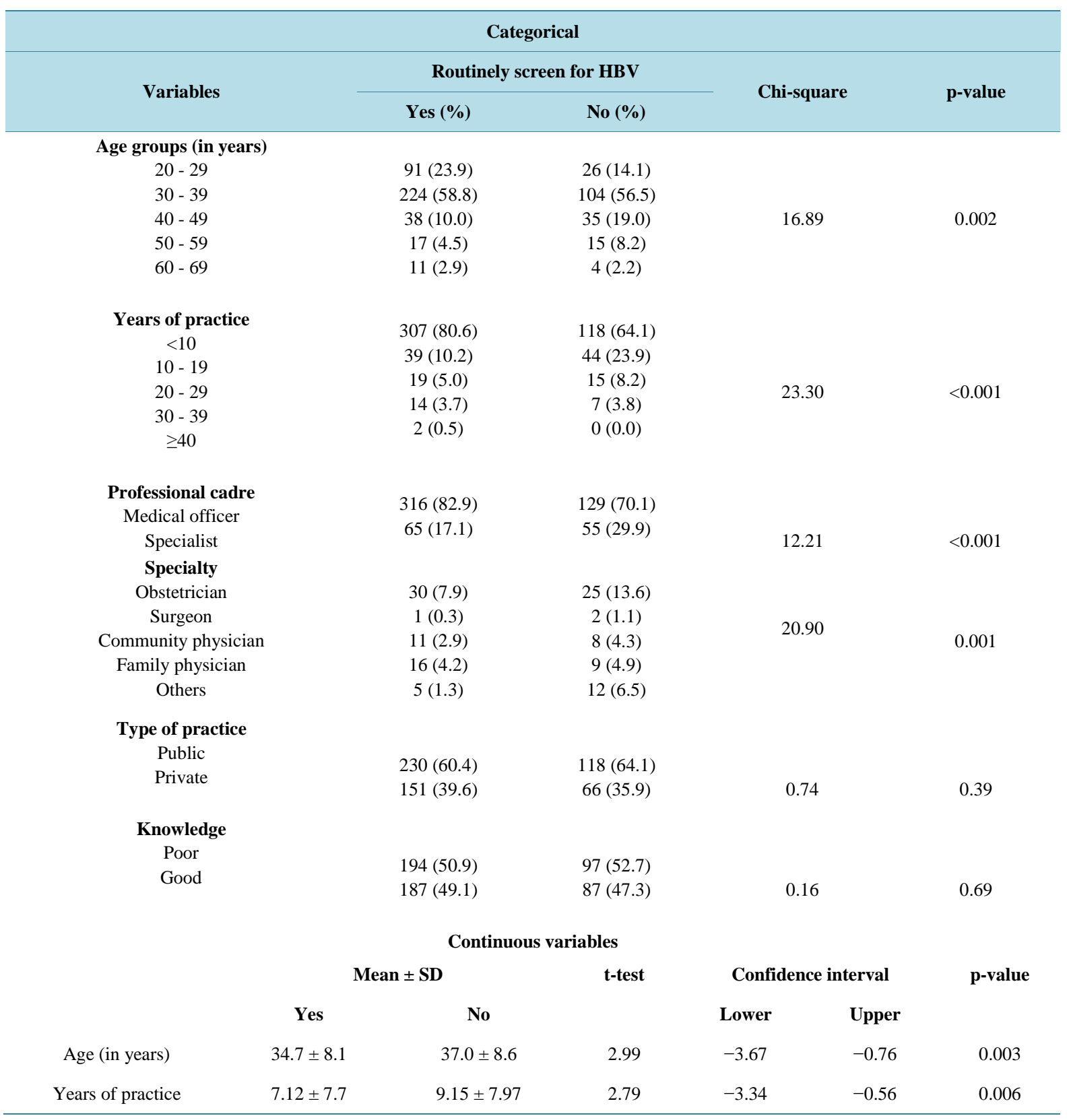


Table 3. Relationship between respondents’ knowledge about HBV and their socio-demographic characteristics.

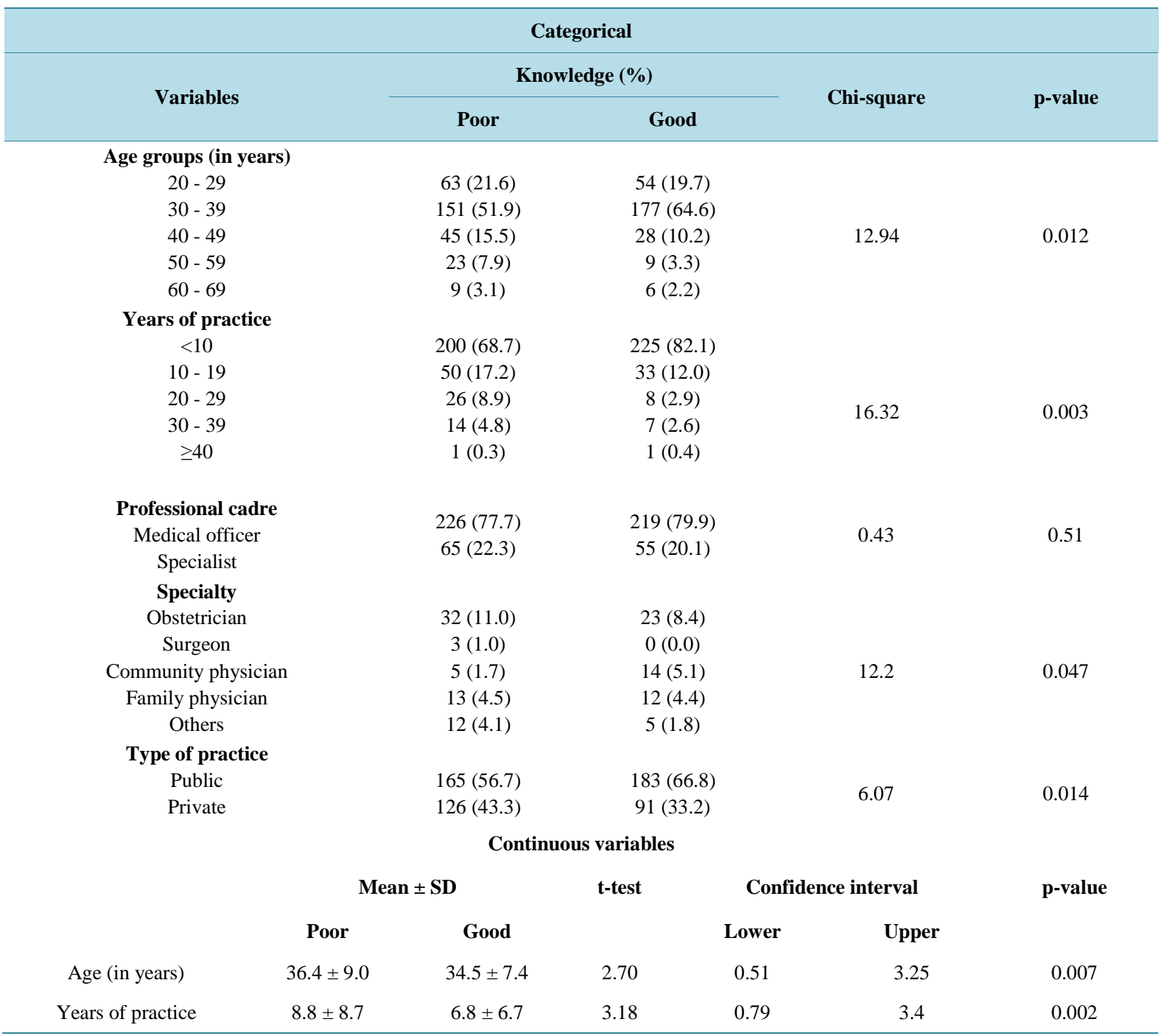

\section{Discussion}

Screening for HBV infection in pregnant women was the practice among $67.4 \%$ of the obstetric care-givers in this study. Although this is a far higher figure compared to the $8.4 \%$ among the obstetric care provider at a tertiary health institution in southwestern Nigeria [11], this is still below expectation from a country known to be hyper endemic for HBV infection. This figure revealed that not all health facilities in southwestern Nigeria routinely screen pregnant women for HBV infection. Routine screening of pregnant women and subsequent management of positive mothers had been shown to reduce the perinatal transmission of the infection which is the commonest route of transmission in endemic regions like Nigeria [9] [10].

Non-universal screening of pregnant women by care providers in this study and in Nigeria at large may be due to the fact that Nigeria has no written national strategy or plan that focuses exclusively or primarily on the prevention and control of viral hepatitis [12]. The care-givers that routinely screen for HBV infection were those in their first decade of practice and of younger generation of doctors (in the third and fourth decade of life); this shows that screening for HBV infection is affected by the years of graduation from medical school, and calls for training and re-training of care-givers in this issue and other related health issues.

Generally, the respondents in this study had poor knowledge of the management of pregnant women test positive for HBSAg, and this will definitely affect their practice regarding the management of this population of women. Therefore there is need for continued medical education to address this knowledge gap if HBV infection 
is to be reduced to the barest minimum in our environment. Although care-givers in the private health institution screened for HBV infection more than those working in the public health institution, they had a poor knowledge of the management of pregnant women tested positive for HBSAg, compared to those working in public health institution made up mostly of specialist resident doctors and consultants; while the care-givers in private establishment may be driven by profit making in testing the pregnant women, those in the public are being driven by knowledge acquisition so as to pass examinations. All these anomalies need be addressed by appropriate policy on HBV infection prevention and control strategy by the government.

Women who are tested positive for HBSAg need to be further tested for HBeAg and other HBV antibodies, because women who are positive for HBeAg have nearly $100 \%$ chance of transmitting HBV to their newborns at birth [13] [14], and up to $90 \%$ of the newborns born to these mothers go on to develop chronic hepatitis B if they do not receive HBIG and HBV vaccine at birth [8] [14]. Many of the respondents were aware of the need for further testing for HBeAg and other HBV antibodies in pregnant women test positive for HBSAg, and the need for the baby to be given HBIG and HBV vaccine at birth, however, only 31.5\% of them knew that HBV vaccine should be given to the baby within 12 hours of birth for maximum effectiveness [14].

About 30\% of the obstetric care providers in this study were aware that pregnant women tested negative for HBSAg with absent antibody to the antigen (anti-HBs) can be vaccinated in pregnancy, although it had been recommended that such women should be vaccinated in pregnancy, especially those women with risk factors to acquire the infection [15].

Certain antiretroviral drugs are now being used for the treatment of pregnant women who test positive for HBSAg to reduce perinatal transmission of the virus especially in those women positive for HBeAg and those with elevated serum levels of HBV DNA [16] The American Association for the study of Liver Diseases Practice Guidelines Committee has provided an evidence-based guideline for the use of these medications [17]. Over $60 \%$ of the respondents in this study were aware of some antiretroviral drugs being used for the treatment of HBSAg positive pregnant women.

\section{Conclusion}

In conclusion, screening for HBV infection in pregnant women is not yet universal in southwestern Nigeria, and the care providers have poor knowledge of the management of the hepatitis B positive mothers. The following is therefore recommended. A national guideline on the prevention and control of HBV infection will go a long way to improve the practice and knowledge of pregnant women care-givers in the management of HBV infection in pregnancy. Furthermore, training and re-training of care providers will also go a long way to improve their knowledge and practice.

\section{References}

[1] Aganga-Williams, O.M., Akanmu, A.S., Akinsete, I. and Njoku, O.S. (1999) Prevalence of Hepatitis B Surface Antigen among Women of Childbearing Age in Lagos, Nigeria. African Journal of Reproductive Health, 3, 45-50. http://dx.doi.org/10.2307/3583228

[2] Soods, S. and Malranker, S. (2010) Seroprevalence of Hepatitis B Surface Antigen, Antigen to The hepatitis C Virus and Human Immunodeficiency Virus in a Hospital-Based Population in Jaipur, Rajasthan. Indian Journal of Community Medicine, 1, 165-169. http://dx.doi.org/10.4103/0970-0218.62588

[3] Cacciola, I., Cerenzia, G., Pollicino, T., et al. (2002) Genomic Heterogeneity of Hepatitis B Virus (HBV) and Outcome of Perinatal HBV Infection. Journal of Hepatology, 36, 426-432. http://dx.doi.org/10.1016/S0168-8278(01)00295-1

[4] Kao, J.H. and Chen, D.S. (2002) Global Control of Hepatitis B Virus Infection. The Lancet Infectious Diseases, 2, 395403. http://dx.doi.org/10.1016/S1473-3099(02)00315-8

[5] Ugwuja, E.I. (2010)Seroprevalence of Hepatitis B Surface Antigen and Liver Function Tests among Adolescents in Abakaliki, South Eastern Nigeria. Internet Journal of Tropical Medicine, 6, 1-6.

[6] Hadler, S.C. and Margolis, H.S. (1989) Viral Hepatitis. In: Evans, A.S., Ed., Viral Infections of Humans, Epidemiology and Control, 3rd Edition, Plenum Medical Book Company, New York, 361-699. http://dx.doi.org/10.1007/978-1-4613-0705-1_13

[7] Stevens, C.E., Neuroth, R.A., Beasley, R.P. and Szimuness, W. (1979) HBeAg and anti-HBe Detection by Radioimmunoassay: Correlation of Vertical Transmission of Hepatitis B Virus in Taiwan. Journal of Medical Virology, 3, 237241. http://dx.doi.org/10.1002/jmv.1890030310 
[8] Joshi, N. and Kumar, A. (2001) Immunoprophylaxis of Hepatitis B Virus Infection. Indian Journal of Community Medicine, 19, 172-183.

[9] CDC (1991) Hepatitis B Virus: A Comprehensive Immunization Strategy for Eliminating Transmission in the United States through Universal Childhood Vaccination: Recommendation of the Advisory Committee on Immunization Practices (ACIP). MMWR, 40, 1-19.

[10] World Health Organization (1998) Progress in the Control of Viral Hepatitis: Recommendation from a WHO Meeting. Bulletin of the World Health Organization, 66, 443-455.

[11] Adebamowo, C.A., Odukogbe, A.A. and Ajuwon, A.J. (1998) Knowledge, Attitude and Practices Related to Hepatitis B Virus Infection among Nigerian Obstetricians and Midwives. Journal of Obstetrics Gynaecology, 18, 528-532. http://dx.doi.org/10.1080/01443619866255

[12] WHO (2013) Global Report on the Prevention and Control of Viral Hepatitis in WHO Member States. Chapter 3, 23.

[13] Institute of Medicine, Hepatitis and Liver Cancer (2010)A National Strategy for Prevention for Prevention and Control of Hepatitis B and C. The National Academies Press, Washington DC.

[14] Apuzzio, J., Block, J.M., Cullison, S., et al. (2012) Chronic Hepatitis B in Pregnancy: A Workshop Consensus Statement on Screening, Evaluation, and Management Part 1. The Female Patient, 37, 22-27.

[15] Mast, E.E., Margolis, H.S., Fiore, A.E., et al. (2006) A Comprehensive Immunization Strategy to Eliminate Transmission of Hepatitis B Virus Infection in the United States; Recommendation of the Advisory Committee on Immunization Practices (ACIP) Part 1: Immunization of Infants, Children, and Adolescents. MMWR-Recommendations and Reports, 54, 1-31.

[16] Gambarin-Gelwa, M. (2007) Hepatitis B in Pregnancy. Clinics in Liver Disease, 11, 945-963. http://dx.doi.org/10.1016/j.cld.2007.08.004

[17] Lok, A.S. and McMahon, B.J. (2009) Chronic Hepatitis B: Update 2009. Hepatology, 50, 661-662. http://dx.doi.org/10.1002/hep.23190 
Scientific Research Publishing (SCIRP) is one of the largest Open Access journal publishers. It is currently publishing more than 200 open access, online, peer-reviewed journals covering a wide range of academic disciplines. SCIRP serves the worldwide academic communities and contributes to the progress and application of science with its publication.

Other selected journals from SCIRP are listed as below. Submit your manuscript to us via either submit@scirp.org or Online Submission Portal.
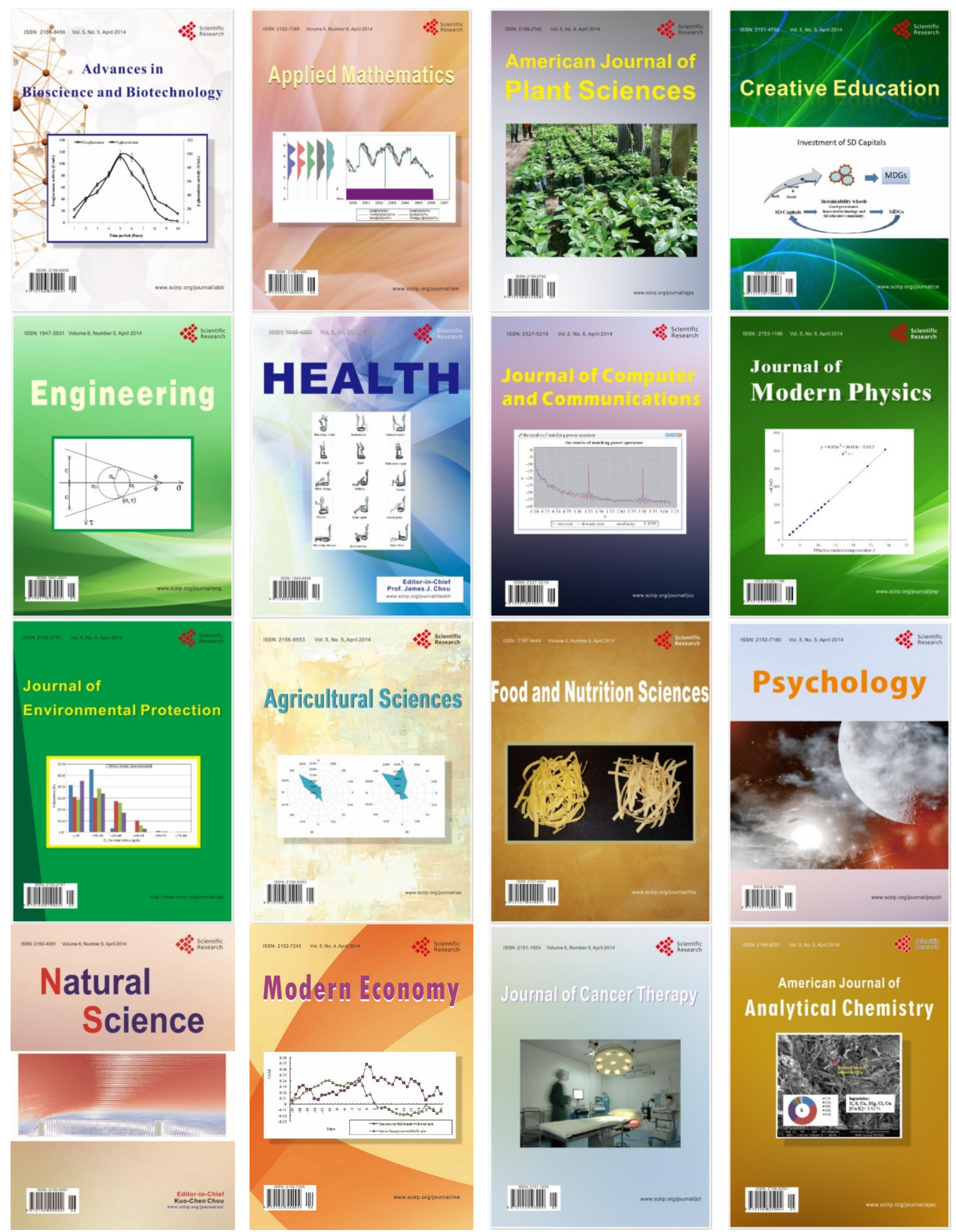